\title{
Informe Comunidad Autónoma Andalucía. Año 2004 (*)
}

\author{
Francisco López Menudo \\ Catedrático de Derecho Administrativo \\ Universidad de Sevilla
}

\section{RASGOS GENERALES}

En medio de la ya tradicional expectación y controversia sobre si las elecciones al Parlamento andaluz deben coincidir o no con las elecciones generales el presidente de la Junta Sr. Chaves González resolvió convocarlas para el 14 de marzo, misma fecha prevista para los comicios a Cortes. Las elecciones andaluzas se celebraron, pues, también bajo los efectos del terrible atentado del 11-M. Las elecciones dieron paso a la apertura de la VII legislatura en Andalucía.

La fecha del 14 de marzo marca verdaderamente un antes y un después en el devenir de esta Comunidad Autónoma. Todos los rasgos generales que podemos inducir de lo acaecido en el año 2004 vienen a converger en el dato principal del holgado triunfo del PSOE en ambas elecciones. A partir de este hecho desaparece como por ensalmo la tensión sostenida entre el Estado y la Junta de Andalucía durante los ocho años de las dos legislaturas regidas por el Presidente del Gobierno Sr. Aznar.

\footnotetext{
* La presente Crónica, elaborada con la colaboración de Juan Antonio Carrillo Donaire, ha sido publicada en el Informe Comunidades Autónomas correspondiente al año 2004. Dicho Informe se publica anualmente desde 1989 por el Instituto de Derecho Público de Barcelona, dirigido actualmente por Joaquín Tornos Más, y está auspiciado por la práctica totalidad de las Comunidades Autónomas, entre ellas la de Andalucía. La obra va dejando constancia anualmente, de manera puntual y sistemática, de la historia política, legislativa y administrativa de cada una de las Comunidades Autónomas y, en suma, del llamado Estado de las Autonomías en su conjunto, amén de estudios monográficos de notable actualidad e interés, relacionados con el tema.

La fecha de cierre de las Crónicas es la de 31 de diciembre del año de referencia. Por esta razón no se recogen acontecimientos habidos con posterioridad. Reproducimos aquí, sin alteración alguna, el texto aparecido en dicho Informe -con autorización del mencionado Instituto- por lo que las valoraciones que se hacen en esta Crónica responden al tiempo y las circunstancias en que fue redactada, con abstracción de lo ocurrido a partir de $1^{\circ}$ de enero de 2005.
} 
Si el contenido principal de nuestro Informe en estos últimos años no ha sido otro que el relato de los numerosos y sonados conflictos que han jalonado la vida política de esta Comunidad Autónoma, en la presente ocasión la tarea se nos ofrece mucho más fácil y, desde luego, menos enojosa, dicho esto en términos absolutamente objetivos, pues todo cuanto hemos de resaltar esta vez se reduce a dejar mera constancia del proceso de deshielo producido y los modos bajo los que se han desactivado los conflictos que se hallaban en liza antes del 14 de marzo. Ello es de celebrar, sin duda, desde cualquier perspectiva que se mire pues en ningún caso es bueno -hagamos abstracción de la dialéctica partidista- que la crispación sea la permanente noticia y que la fuerza de ésta obligue a desatender el análisis de la acción de gobierno en sí misma considerada, con todos sus posibles claroscuros. A la postre, la confrontación sostenida acaba generando una dinámica de la afrenta, un lenguaje a veces manido omnipresente en cualquier discurso o mensaje y un razonar al modo de un círculo vicioso que suele acabar eclipsando, socorridamente, la apreciación de la realidad y el sentido de la autocrítica. Por tanto, cualquiera que hubiere sido la circunstancia que ha propiciado el cese de las hostilidades sería digna de celebrar, si consideramos como un bien la normalidad y el abandono de unas tensiones que rayaban ya en el empecinamiento y el desorden.

El restablecimiento de la "paz exterior" se ve complementada por la ausencia de conflictos internos dada la amplia mayoría absoluta lograda en Andalucía por el partido del Sr. Chaves, lo que, por una parte, le ha permitido prescindir del Partido Andalucista como socio en el Gobierno, rescatando las dos carteras que los andalucistas ostentaban a cambio del apoyo en la Cámara de sus tres parlamentarios. Por otra parte, el descalabro del Partido Popular de Andalucía ha colocado a esta formación en la tesitura de tener que mirar prioritariamente a su reconstitución y a mejorar su propia imagen. Lo mismo cabe decir de Izquierda Unida Los Verdes-Convocatoria por Andalucía, respecto del cual ha disminuido la necesidad de hacerle concesiones que, en cambio, sí le fueron hechas durante la legislación precedente. Un panorama, por tanto, sumamente cómodo que ha facilitado al Presidente de la Junta su invitación al diálogo y al impulso de acciones conjuntas, entre ellas, la reforma del Estatuto.

Si a todo lo anterior se une el hecho de que durante el ejercicio sólo ha sido aprobada una Ley, aparte de las consabidas de Presupuestos y de Acompañamiento (no se ha dado el paso de suprimir este tipo de Ley, lamentablemente); que el número e importancia de las disposiciones reglamentarias ha sido menor que el de otros años -lo que es explicable tratándose de un año electoral-; la ausencia, por la razón que se acaba de mencionar, del debate so- 
bre el estado de la Comunidad Autónoma; la inexistencia de conflictos constitucionales a partir del día 14 de marzo; y la ausencia de incidentes políticos o de sucesos realmente trascendentes, puede decirse que el año 2004 ha sido unos de los menos complejos que pueden recordarse.

Un mes antes de las elecciones del 14 de marzo, cuando aún se daba por segura la victoria del Partido Popular en el Congreso de los Diputados -se especulaba entonces si obtendría o no la mayoría absoluta a la vista del ascenso que iba experimentando el PSOE a la luz de los sondeos- en Andalucía esos mismos sondeos pronosticaban el triunfo claro de los socialistas (53/54 escaños), cercano a la mayoría absoluta establecida en 55, y asimismo se estimaba que el PP obtendría 44/45 escaños, es decir, un retroceso de uno o dos escaños respecto a las anteriores elecciones autonómicas del año 2000. Por tanto, las consabidas especulaciones sobre que hubiera ocurrido en las elecciones generales si no se hubiera producido el atentado del 11-M, no tenían cabida en el caso de las elecciones andaluzas ya que la victoria del PSOE estaba cantada de antemano, aunque quizás no con la holgura que al final resultó.

De igual modo, las encuestas así como las opiniones que se hallaban en el ambiente señalaban que un factor determinante del "castigo" que sufriría en Andalucía el Partido Popular era el sentimiento de la población del trato discriminatorio proveniente del Gobierno central, simbolizado en el impago de la deuda pendiente de la financiación referida al quinquenio 1997-2001. Una deuda reconocida por los Tribunales y por el Gobierno central pero cuyo pago se vio sistemáticamente demorado, unas veces bajo argumentos de tipo técnico y otras por "razones" nacidas de esa dinámica, antes aludida, del reproche recíproco y la devolución del agravio. Pudo el Gobierno haber optado por saldar el débito e incluso pareció que lo haría "in extremis" poco antes de la cita con las urnas del 14 de marzo, pero la estrategia finalmente seguida fue la de anunciar, en plena campaña electoral, que el Gobierno atendería el pago de la deuda y demás reivindicaciones pendientes tan pronto el PP ganara las elecciones en Madrid y en Andalucía, lema éste aireado con fuerza por la aspirante a la presidencia de la Junta y de algún ministro del Gobierno. Un mensaje ciertamente arriesgado y a todas luces erróneo a la vista de los resultados electorales. No cabe duda que el electorado pasó factura por ello.

En las elecciones al Parlamento andaluz votó el 75,82 por ciento del censo, unos cuatro millones y medio de personas con capacidad de sufragio. Los resultados fueron los siguientes: 


\begin{tabular}{|c|c|c|c|c|c|c|c|c|}
\hline \multicolumn{9}{|c|}{$\begin{array}{c}\text { RELACIÓN DE VOTOS CORRESPONDIENTES A CADA UNO DE LOS PARTIDOS, } \\
\text { FEDERACIONES Y COALICIONES O CANDIDATURAS QUE HAN OBTENIDO } \\
\text { ESCAÑOS Y NÚMERO DE VOTOS }\end{array}$} \\
\hline $\begin{array}{l}\text { Juntas } \\
\text { Electorales }\end{array}$ & \multicolumn{2}{|c|}{$\begin{array}{l}\text { Partido Socialista Obrero } \\
\text { Español de Andalucía }\end{array}$} & \multicolumn{2}{|c|}{$\begin{array}{c}\text { Partido Popular } \\
\text { de Andalucía }\end{array}$} & \multicolumn{2}{|c|}{$\begin{array}{l}\text { Izquierda Unida } \\
\text { Los Verdes-Convocatoria } \\
\text { por Andalucía }\end{array}$} & \multicolumn{2}{|c|}{$\begin{array}{c}\text { Partido } \\
\text { Andalucista }\end{array}$} \\
\hline ALMERÍA & 6 & 140.730 & 5 & 127.998 & 0 & 11.739 & 0 & 13.330 \\
\hline CÁDIZ & 8 & 307.749 & 5 & 205.625 & 1 & 42.459 & 1 & 46.810 \\
\hline CÓRDOBA & 7 & 226.246 & 4 & 151.857 & 1 & 55.474 & 1 & 31.619 \\
\hline GRANADA & 7 & 255.465 & 5 & 184.691 & 1 & 36.949 & 0 & 22.541 \\
\hline HUELVA & 7 & 145.170 & 3 & 78.997 & 0 & 20.103 & 1 & 22.010 \\
\hline JAÉN & 7 & 222.596 & 4 & 135.825 & 1 & 27.884 & 0 & 23.943 \\
\hline MÁLAGA & 8 & 349.404 & 6 & 254.571 & 1 & 55.624 & 1 & 49.017 \\
\hline SEVILLA & 11 & 613.185 & 5 & 287.210 & 1 & 86.798 & 1 & 67.404 \\
\hline TOTAL & 61 & 2.260 .545 & 37 & 1.426 .774 & 6 & 337.030 & 5 & 276.674 \\
\hline
\end{tabular}

Los votos obtenidos por el PSOE sobre el total de los emitidos representan el 50,2 por ciento. Ello se tradujo en 61 escaños, 9 más que en el año 2000. Rebasa en 6 escaños el número necesario -55- para la mayoría absoluta.

El PP, con el 31,7 por ciento, obtuvo 37 escaños, 9 menos que en 2000 y muy por debajo de los pronósticos. Fueron sus peores resultados desde 1990, desde el que se ha producido la siguiente evolución: 26 (1990), 41 (1994), 40 (1996), 46 (2000) y 37 (2004). Los populares sufren un auténtico desplome si se tiene en cuenta que en las últimas elecciones municipales de sólo un año atrás ganaron -aquí su primacía en el voto urbano- en seis de las ocho capitales de provincia, y en las autonómicas que comentamos sólo obtuvieron mayor número de votos en las capitales de Cádiz, Almería, Córdoba y Granada. A nivel provincial perdieron en todas las circunscripciones, con grandes diferencias.

Sería un error identificar la caída del PP andaluz con el mismo descalabro sufrido por la formación nacional de este Partido y la tragedia del 11-M. Ya hemos indicado que en esta Comunidad se daban causas específicas al margen del tema de la participación española en la guerra de Irak y sus derivaciones, siendo llamativo el dato de que en todas las provincias los andaluces 
dieran mayor número de votos a las listas del PP para el Congreso de los Diputados que al Parlamento Andaluz. El PP obtuvo de Andalucía para el Congreso 23 escaños, cinco menos que en el año 2000, y es significativo que uno de esos escaños perdidos lo fuera en Sevilla donde el PP tenía como cabeza de lista al Sr. Arenas Bocanegra, ministro especialmente involucrado en el tema del impago de la deuda.

IU Los Verdes-Convocatoria por Andalucía, con el 7,5 por ciento, obtuvo 6 escaños, los mismos que en 2000, aunque disminuyendo el porcentaje de votos.

El PA, con el 6,1 por ciento, también disminuyendo el porcentaje de votos, obtuvo 5 escaños, los mismos que en 2000. Este partido celebró su Congreso nacional a primeros de diciembre, resultando elegido como Secretario General D. Julián Álvarez, ex Alcalde de Écija, quien desbancó así a D. Antonio Ortega García, líder andalucista que ocupó la cartera de Turismo y Deporte en el anterior gobierno del Sr. Chaves.

Es de reseñar el revés sufrido por el PSA liderado por Pedro Pacheco (0,94 por ciento) y la aparición sin éxito de Foro Andaluz, la formación impulsada por el ex ministro cordobés Manuel Pimentel.

Nada más producido el escrutinio del 14 de marzo, los representantes de ambos gobiernos se apresuraron a declarar la voluntad inmediata de llegar a acuerdos y cancelar los conflictos mediante el desistimiento por cada parte de los recursos residenciados en el TC, propósito éste que, dicho sea de paso, de seguro sería bien recibido por el Alto Tribunal al liberarle de resolver un buen cúmulo de controversias estancadas durante demasiados años. Salvo en dos conflictos concretos (el de las pensiones no contributivas y el de los Parques Nacionales resuelto por la reciente Sentencia 194/2004) el TC ha quedado inédito en esta larga historia de tensiones, lo que no es precisamente de celebrar desde la perspectiva del funcionamiento del Estado.

Lógicamente, el primer asunto a liquidar fue el de la deuda pendiente de la financiación por el quinquenio 1997-2001. Se han manejado cifras contradictorias sobre el montante exacto de la deuda. Pero lo sustancial a resaltar en este caso es que el Ministro Sr. Solbes y el Consejero de Economía Sr. Griñán Martínez zanjaron el tema fijando la cifra en 2.500 millones de euros, cifra ésta idéntica a la que el Gobierno andaluz estuvo dispuesto a aceptar del Gobierno del PP si éste la pagaba de inmediato antes de las elecciones, pago que se frustró como hemos ya señalado. Quizás este hecho venga a subrayar por sí 
mismo el error que supuso la postura del Gobierno del Sr. Aznar en este tema; voces de este mismo partido así lo han reconocido.

La conformidad del Ejecutivo andaluz con esta cifra, acordada en firme con el nuevo Gobierno del PSOE ha generado protestas en los restantes partidos andaluces, especialmente del PP, habiendo denunciado éstos que dicho pacto supone la condonación al Gobierno del Sr. Rodríguez Zapatero de la diferencia hasta 4.416 millones de euros -que incluye la partida correspondiente al censo de población, causante del famoso conflicto- en que el Parlamento andaluz tenía cuantificada la deuda, amen de la acusación de rebajar también las exigencias en cuanto a la inmediatez del abono al aceptar su pago a plazos en cuatro años, condición ésta que pasó a ser considerada por el Gobierno andaluz como una cuestión menor. La deuda fue formalmente satisfecha mediante el Real Decreto-ley 7/2004 de 27 de septiembre, fijándola en 2.500.034.925 euros y declarando que su pago se haría durante el ejercicio de 2004.

Lo cierto es que dicho acuerdo, alcanzado en Junio, motivó la retirada por parte del Parlamento andaluz y del Consejo de Gobierno de todos los recursos constitucionales y contencioso administrativos planteados contra las Leyes relacionadas con el sistema de financiación generador de la deuda: modificación de la LOFCA, Cesión de Tributos del Estado, Presupuestos del Estado del citado quinquenio. (Vid. los desistimientos infra). Y por parte del Gobierno central se produjeron "gestos" correlativos; así los desistimientos de sus recursos ante el TC en el espinoso asunto de la Caja de Ahorro cordobesa "Cajasur" -cuya historia hemos contado en anteriores informes- en el que finalmente el Estado, mediante la modificación de la LORCA, sustrajo esta Caja de la Iglesia católica del ámbito competencial de la Junta. Hay que significar que esta entidad solicitó del TC ser oída antes de que resolviera sobre el desistimiento instándole a proseguir el procedimiento de oficio. No obstante, a mediados de diciembre el presidente de Cajasur, D. Miguel Castillejo suscribió con el Consejero de Economía un acuerdo que perfila la vuelta de la Caja a la tutela de la Junta. El ultimo episodio de esta larga historia es que el acuerdo en cuestión ha suscitado discrepancias que están por resolver en la actualidad.

También se avino el Estado a abandonar los litigios constitucionales relativos al Plan de Ordenación de los Recursos Naturales de la Isla de Alborán y a la concesión de subvenciones públicas estatales en las áreas de influencia de los Parques Nacionales para 2004. Pero, sin duda, uno de los "guiños" más expresivos del nuevo clima de entendimiento fue la retirada del recurso de inconstitucionalidad contra la Ley andaluza 7/2003 reguladora de la investiga- 
ción en Andalucía con las llamadas "células madre", asunto éste que motivó el enésimo y último pulso de resonancia sostenido entre el Estado y la Junta de Andalucía en las dos legislaturas ya finalizadas.

A estos fáciles arreglos logrados durante el año 2004 hay que sumar otros igualmente positivos, en el ámbito del traspaso de competencias, tal como el de la cuenca hidrográfica intracomunitaria del Sur de España (incomprensiblemente anclado en vía muerta durante tantos años); o la búsqueda de una fórmula para la cogestión de la cuenca del Guadalquivir, un primer paso, al menos, que conduzca a un tratamiento distinto al que se ha venido dispensando a esta cuenca, tan asentada sobre Andalucía, cuyo río principal nace y muere en su territorio.

Se cierra así un ciclo (1996-2004) que generó 61 litigios ante el TC, 47 planteados por la Junta (32 recursos de inconstitucionalidad y 15 conflictos de competencia) y 14 interpuestos por el Gobierno de la Nación (10 recursos y 4 conflictos), etapa en la que la Comisión Mixta de Transferencias se reunió sólo para el traspaso en materia de Justicia (1997) y las políticas activas de empleo (2002), otro enconado asunto que alcanzó en su momento más virulencia de la que posiblemente era razonable.

El nuevo clima de entendimiento ha sido visto por los partidos de la oposición como ocasión propicia para rescatar la vieja reivindicación de la "deuda histórica" dimanante de la Disposición Adicional 2ª del Estatuto, que dice así: "1. Dadas las circunstancias socioeconómicas de Andalucía, que impiden la prestación de un nivel mínimo en alguno o algunos de los servicios efectivamente transferidos, los Presupuestos Generales del Estado consignarán, con especificación de su destino y como fuentes excepcionales de financiación, unas asignaciones complementarias para garantizar la consecución de dicho nivel mínimo. 2. Los criterios, alcance y cuantía de dichas asignaciones serán fijados para cada ejercicio por la Comisión Mixta paritaria Estado-Comunidad Autónoma a que se hace referencia en el apartado 2 de la Disposición transitoria sexta."

La llamada "deuda histórica" es, pues, un concepto distinto de la deuda correspondiente a la financiación antes relatada, aunque con mucha frecuencia han sido confundidas, incluso por la clase política, quizás porque la deuda de la financiación también a su manera se ha erigido en "histórica", eclipsando a la otra durante una larga etapa en la que su reconocimiento y pago tenía pocos visos de prosperar. No obstante, los Presupuestos Generales de la Junta de Andalucía han venido consignando cada año la cifra -simbólica- de 120 
millones de euros, manteniendo así viva la reivindicación; e incluso el propio Gobierno del Sr. Aznar hizo el pago de una anualidad en 1997, sin continuidad después.

En este nuevo embate por la genuina "deuda histórica" han puesto especial empeño los tres partidos de la oposición al PSOE, quizás también con la intención política de comprobar el grado de beligerancia que el Presidente Sr. Chaves está dispuesto a desplegar frente al Gobierno central de su mismo partido. La posición del Presidente, según resulta de sus propias manifestaciones, puede calificarse de moderada pues aunque el montante cuantificado en 1996 (en la fase final del Gobierno de Felipe González) fue equivalente a los 1.200 millones de los euros actuales, el Sr. Chaves ha estimado que esa cuantificación hay que tomarla sólo como punto de partida, debiendo valorarse cómo se encuentre en la actualidad cada servicio en relación con el "nivel medio", lo que requiere el estudio correspondiente; por otra parte, la reivindicación no se negociaría por la vía bilateral sino que se plantearía en el Consejo de Política Fiscal y Financiera; y en cuanto al momento, la perspectiva es la de activar la petición a lo largo de la legislatura.

No podríamos cerrar esta impronta del año 2004 sin una referencia a la situación de la reforma del Estatuto. En informes anteriores hemos dado cuenta de que la iniciativa al respecto se remonta al año 2001 en que con ocasión del XX aniversario del Estatuto de Andalucía, el Presidente Chaves lanzó este propósito en el Debate sobre el Estado de la Comunidad Autónoma. Por tanto, este proyecto de corte moderado, surgido en un momento histórico que pudiéramos denominar "tranquilo", se ha visto condicionado y podemos decir que rebasado por los acontecimientos sobrevenidos. Todavía a finales de 2003, en un momento en el que el Partido Popular ejercía en el Parlamento andaluz la presión inherente a su fuerza numérica y a sus concepciones sobre la intangibilidad de la Constitución y del Estatuto, la cuestión de cual sería la altura de la reforma y las innovaciones a introducir era algo del dominio directo del Presidente quien presentó ante el Parlamento -el 16 de diciembre de 2003- un documento con los diez objetivos básicos de la reforma. Mientras que unos de esos objetivos fueron entonces considerados como insignificantes o de segunda fila -por parte de IU y del PA-, otros fueron calificados como escandalosos -aquí las protestas del PP-, tal como la creación de una Agencia Tributaria no obstante estar circunscrita a los tributos propios o cedidos por el Estado.

En este ambiente tan dispar subyacían sin embargo dos opciones muy simples, siempre bajo el común denominador de velar por el estricto respeto 
a la Constitución: paralizar la reforma, no contribuyendo así a propagar el movimiento reformista puesto ya en marcha en Cataluña y el País Vasco; o aprovechar la oportunidad para hacer una reforma profunda que sirviera para aleccionar erga omnes sobre el nivel máximo tolerable por la Constitución. Una tercera opción podía ser la de ralentizar el proceso y esperar el desarrollo de los acontecimientos. Lo que sí parece claro es que en tal contexto resultaba ya inoportuno vincular la reforma del Estatuto andaluz a una serie de objetivos predeterminados -como los propuestos en su día por el Presidente de la Junta- con abstracción de lo que estuviera ocurriendo en otras latitudes.

Esta tercera opción es la que a la postre se ha impuesto de hecho. Tras la apertura de la nueva Legislatura queda desechado, como modus operandi, la presentación por el gobierno autonómico de un Proyecto de reforma a debatir en la Cámara. Se ha optado porque el texto articulado del proyecto de Estatuto sea elaborado en el seno de la Comisión parlamentaria de Desarrollo estatutario, constituida al efecto el 18 de junio, habiéndose nombrado una Ponencia compuesta por representantes de los cuatro grupos parlamentarios (3, PSOE; 2, PP; 1, IU; 1, PA) que es la directamente encargada de la redacción del texto cuyo primer borrador se anuncia para mediados de 2005. Hay que señalar que el PP se ha integrado de buen grado en este diseño.

Desde el mes de septiembre de 2004 han ido desfilando por dicha Comisión numerosos comparecientes de los más diversos ámbitos y estratos (ex presidentes de la Junta, Alcaldes, Rectores, etc. etc.) con el fin de informar a la Cámara sobre sus experiencias y propuestas de reforma; un trámite de audiencia muy denso y prolongado cuyas aportaciones serán, sin duda, difíciles de amalgamar. Paralelamente, se crea por el Decreto 497/2004 un Consejo Asesor para la Modernización del Estado de las Autonomías adscrito a la Consejería de la Presidencia, compuesto por diez miembros: dos ex presidentes andaluces del Tribunal Constitucional (D. Pedro Cruz Villalón y D. Manuel Jiménez de Parga), dos ex presidentes de la Junta de Andalucía (D. Rafael Escuredo y D. José Rodríguez de la Borbolla) y seis miembros pertenecientes al cuerpo de catedráticos de Universidad, órgano que por su configuración y solvencia técnica parece estar llamado a desarrollar un importante papel, aunque habrá que ver cómo funcione la conexión de este cualificado grupo de expertos -a través del puente de dicha Consejería- con la Comisión parlamentaria constituida. No es preciso encarecer la trascendencia de una colaboración técnica de calidad a la hora de redactar un Estatuto, tarea esta que amén de su gran dimensión política exige conocimientos diversos y sobre todo dominio del Derecho en sus múltiples vertientes. 
Dentro de este contexto de la reforma estatutaria se constituyó en el mes de junio una plataforma cívica autodenominada "Andaluces levantaos" (una frase del himno de Andalucía) impulsada por cuatro personalidades de la política harto conocidas: el profesor D. Manuel Clavero Arévalo, ex ministro de las Regiones y de Cultura en el Gobierno de Adolfo Suárez; D. Rafael Escuredo, ex presidente de la Junta; Don Alejandro Rojas Marcos, ex Presidente del Partido Andalucista; y D. Manuel Pimentel, ex Ministro de Trabajo), cuya finalidad, según reza en sus manifiestos, es la de avivar la conciencia de la ciudadanía sobre los cambios que se avecinan y evitar que Andalucía pueda quedarse descolgada del techo que puedan alcanzar las llamadas Comunidades históricas. Celebró su asamblea constituyente en Málaga, el 24 de septiembre.

\section{PARLAMENTO}

Con su nueva composición surgida de las elecciones del 14 de marzo, se constituyó el día 31 siguiente bajo la presidencia de Dña. Maria del Mar Moreno, quedando compuesta la Mesa por tres vicepresidencias y tres secretarías ocupadas proporcionalmente por representantes de los cuatro grupos parlamentarios. Del mismo modo quedaron repartidas las presidencias de las diecisiete Comisiones parlamentarias.

Cabe destacar que el portavoz del Grupo socialista Sr. Caballos Mojeda -que ha ejercido esta función durante cuatro legislaturas consecutivas- fue cesado el 2 de septiembre como efecto final de la crisis ocurrida durante el verano en la Secretaría provincial del PSOE de Sevilla en la que el Sr. Caballos perdió ante el aspirante Sr. Viera Chacón (quien había sido nombrado Delegado del Gobierno en la Comunidad Autónoma), auspiciado éste para regir dicha Secretaría por el Presidente Sr. Chaves. Le sucedió en el cargo de portavoz el diputado por Córdoba Manuel Gracia Navarro, ex Consejero de la Junta.

\section{A) Actividad legislativa}

Las Leyes aprobadas en el ejercicio son las que se relacionan seguidamente. Se corresponden todas ellas con Proyectos de Ley presentados por el Consejo de Gobierno:

Ley 1/2004 de 17 de diciembre, de creación del Consejo Audiovisual de Andalucía. Este organismo se configura como autoridad independiente encargada 
de velar por el respeto de los derechos, libertades y valores constitucionales y estatutarios, así como por el cumplimiento de la normativa vigente en el ámbito de los medios audiovisuales en Andalucía, en relación con los contenidos y publicidad audiovisuales. La elección de sus miembros por el Parlamento de Andalucía (entre personas de reconocido prestigio y competencia en el ámbito de la comunicación audiovisual, científico, educativo, cultural o social), la duración de su mandato (más tiempo que el mandato parlamentario) y su actuación independiente del Gobierno y Administración autonómica confieren al Consejo Audiovisual de Andalucía el carácter de una "Administración independiente”, que armoniza con el régimen de autonomía funcional que preside el ejercicio de sus funciones. La Ley ha visto la luz tras ocho años de espera.

Ley 2/2004 de 28 de diciembre, de Presupuestos Generales para 2005. Su montante global, de 24.451 millones de euros, representan un incremento del 10,3 por ciento respecto al del ejercicio anterior. Según el propio Consejero de Economía, el presupuesto se inspira en una política basada en el aumento de la productividad, la cohesión social y el fortalecimiento del diálogo entre los sectores público y privado.

Ley 3/2004, de 28 de diciembre, de medidas tributarias, administrativas y financieras. La conocida como Ley de Acompañamiento recoge una serie de normas que se relacionan directa o indirectamente con los objetivos presupuestarios, como por ejemplo puedan ser la regulación de beneficios fiscales o el establecimiento de tasas, al tiempo que se contemplan otras medidas cuya relación con el presupuesto es bastante más lejana -o simplemente inexistente-, tales como la creación de la Agencia Andaluza del Agua o las modificaciones de las Leyes de Universidades, de Comercio Interior, de Ordenación del Territorio y de Cajas de Ahorros. Este ejercicio brindaba la ocasión de haber seguido el ejemplo del Estado, suprimiendo este tipo de Ley, cada vez más impopular, no sólo por lo que suponen en sí respecto al procedimiento ordinario, sino por los vicios adicionales que suelen añadírsele durante su oscuro y vertiginoso proceso final de formación. Hubiera sido muy oportuno prescindir de este instrumento, máxime en un ejercicio como el presente en el que la producción legislativa ordinaria ha sido especialmente reducida.

Las demás iniciativas legislativas producidas durante 2004 y que se hallaban en tramitación al final de dicho año se inscriben todas en la VII Legislatura que se abrió con las elecciones del 14 de marzo. Antes del 31 de ese mismo mes la Cámara no celebró sesiones. 


\section{Proyectos de Ley}

De creación del Colegio Oficial de Ingenieros en informática.

De creación del Colegio Oficial de Ingenieros Técnicos en informática.

De régimen de las organizaciones interprofesionales agroalimentarias en el ámbito de la Comunidad Autónoma de Andalucía.

De creación del Comité Andaluz para la Sociedad del Conocimiento.

De modificación de la Ley 8/1987, de 9 de diciembre, de creación de la Empresa Pública de la Radiotelevisión de Andalucía y regulación de los servicios de radiodifusión y televisión gestionados por la Junta de Andalucía.

De Fundaciones.

De creación del Colegio Oficial de Educadores Sociales.

\section{Proposiciones de ley}

Proposición de Ley de modificación de la Ley 5/1988, de 17 de octubre, de Iniciativa legislativa popular y de los Ayuntamientos. (Presentada por el Grupo Parlamentario Izquierda Unida Los Verdes-Convocatoria por Andalucía).

Proposiciones de Ley: reguladora de la actividad publicitaria de las Administraciones en Andalucia; sobre de modificación de la Ley por la que se modifica la Ley 1/1986, de 20 de enero, Electoral de Andalucía; relativa al Consejo Consultivo de Andalucía; relativa a modificación de la Ley de Incompatibilidades de Altos Cargos de la Administración Andaluza y de Declaración de Actividades, Bienes e Intereses de Altos Cargos y otros Cargos Públicos; sobre el estatuto de los Ex-Presidentes de la Junta de Andalucia; y de reforma del Reglamento del Parlamento andaluz. Se trata de un paquete de medidas, llamadas de "impulso democrático" suscrito por todos los grupos parlamentarios excepto el Popular de Andalucía.

\section{B) Actividad parlamentaria en general.}

1. Debates generales ante el Pleno

Debate de Investidura.

En las sesiones plenarias del Parlamento de Andalucía para la investidura del candidato a la Presidencia de la Junta de Andalucía, que tuvieron lugar los días 20 y 21 de abril de 2004, D. Manuel Chaves González fue investido Presidente por quinta vez consecutiva, al ser elegido por la mayoría absoluta de los representantes del Parlamento autonómico. El Presidente Chaves revalidó su cargo con el voto favorable de 61 de los 109 diputados que integran la Cáma- 
ra (los pertenecientes al PSOE); 36 votos en contra (del Grupo del Partido Popular de Andalucía) y la abstención de 11 parlamentarios (los 6 diputados de Izquierda Unida Los Verdes Convocatoria por Andalucía, y los 5 del Partido Andalucista).

El Sr. Chaves González inició su intervención resaltando el diálogo como principal herramienta de trabajo para la VII Legislatura y anunció como primera medida de gobierno una ronda de encuentros con todos los partidos políticos de la Cámara, los sindicatos, empresarios, las entidades representativas de la sociedad civil y la FAMP.

El discurso tuvo tres ejes conductores: la reforma estatutaria, el reestablecimiento del diálogo con el Gobierno central y el desarrollo de la llamada "segunda modernización de Andalucía”. Por lo que respecta a la reforma del Estatuto, el candidato abogó por el diálogo y el consenso parlamentario a fin de hacer posible lo que calificó de "irreversible proceso de modernización autonómica”. Tal proceso debe acompañarse, a juicio del candidato, por la reforma del Título VIII y, sobre todo, del artículo 169 de la Constitución, de modo que sea posible hacer del Senado una cámara de primera lectura para cuestiones de alcance autonómico. Para ese orden de cuestiones y otras en que las relaciones Estado-Comunidad Autónoma habían alcanzado un gran nivel de estancamiento y crispación en la legislatura anterior, el candidato lanzó una propuesta abierta de diálogo con el Gobierno central, al tiempo que se felicitaba por la formalización de un foro multilateral, la Conferencia de Presidentes de las Comunidades Autónomas, en la que hacer posible el diálogo colectivo entre todas las autonomías y el Estado. En el terreno de las propuestas concretas, el candidato anunció la apertura de negociaciones con el Gobierno y la Administración central en torno a las siguientes cuestiones: liquidación del sistema de financiación correspondiente al periodo 1997-2001; fijación de un calendario para la concreción de los traspasos pendientes; acuerdos para la cofinanciación de infraestructuras; y, finalmente, replanteamiento de los conflictos y recursos planteados ante el Tribunal Constitucional por una y otra parte.

Tras esta serie de propuestas de calado político-institucional, el candidato comenzó a desgranar las medidas que emprendería su Gobierno sentando como presupuesto que "la Segunda Modernización de Andalucía será el programa de gobierno". Los anuncios que el candidato hizo en este sentido se corresponden con las distintas medidas sectoriales que ya habían sido avanzadas en la campaña electoral. En el desglose de estas medidas destacó el objetivo de alcanzar durante la VII Legislatura la cifra de tres millones de ocupados en 
Andalucía. En este sentido, el Gobierno de la Junta de Andalucía contará con dos instrumentos esenciales: por una parte, el sistema educativo y formativo, y por otra, las ayudas de la Administración. En el contexto de las medidas de fomento, el candidato reveló la creación del "ticket emprendedor", que integrará las ayudas en concepto de autoempleo y apoyo inicial, con un importe de hasta 9.000 euros y un plazo máximo de pago de dos meses.

La importancia de la Universidad en el desarrollo tecnológico se pretende potenciar con la creación de la Consejería de Innovación, Ciencia y Empresas. Su cometido será -en palabras del candidato- "gestionar todas las acciones del Gobierno en materia de I+D+i y de apoyo empresarial". En este sentido, el Presidente en funciones anunció que la Junta de Andalucía duplicaría en los próximos cuatro años su gasto en $\mathrm{I}+\mathrm{D}+\mathrm{i}$ y que serán las Universidades quienes lideren la implantación de la sociedad del conocimiento en Andalucía. Por su parte, el sector empresarial no quedará -según el candidato- al margen de este proceso, ya que las empresas que desarrollen un proyecto con algún centro investigador público recibirán automáticamente "una ayuda para un proyecto posterior al menos por el mismo importe que el que ellas hayan invertido anteriormente".

En el capítulo laboral, el candidato avanzó que el Servicio Andaluz de Empleo (SAE) prestará servicios de intermediación tanto a los desempleados como a las empresas y que a cada demandante de empleo inscrito en el SAE se le confeccione un itinerario personalizado de inserción. Junto a ello, las medidas que se emprenderán en el campo de la estabilidad y la siniestralidad laboral se ajustarán el contenido de un Libro Blanco que a tal fin redactará una Comisión de Expertos cuya creación impulsará el Gobierno autonómico.

En materia de Turismo, el candidato apostó por reforzar la promoción con una unidad específica dedicada a crear opinión en los mercados emisores, potenciar la comercialización a través de internet y completar la modernización tecnológica con la creación del Instituto de Tecnología Aplicada a la Producción Turística. Asimismo, defendió la importancia para la Comunidad Autónoma de los sectores agrarios afectados por reformas de sus OCM -olivar, algodón y tabaco- recalcando su apoyo al mantenimiento de las ayudas públicas dirigidas a estas actividades y a las medidas dirigidas al incremento de la calidad y la competitividad en el proceso productivo.

En relación al problema de la vivienda, la mayor novedad consistió en el anuncio de la creación de la Agencia Andaluza de Alquileres como órgano llamado a contribuir a cubrir los riesgos básicos que corren los propietarios: im- 
pago, desperfectos y disponibilidad de la vivienda. Asimismo, el candidato destacó que los próximos cuatro años el Gobierno andaluz prevé registrar 250.000 actuaciones de habilitación de viviendas entre nueva planta y rehabilitación, de modo que el $50 \%$ de los nuevos hogares que se constituyan en este periodo puedan hacerlo bajo algún régimen de vivienda protegida. Estas medidas van ligadas a otras de aplicación fiscal, como la exención de la cuota autonómica del IRPF para los contribuyentes, unos 700.000, que no superen los 12.000 euros netos al año.

Respecto a la mejora de las infraestructuras, el candidato avanzó que esta legislatura conocerá la entrada en funcionamiento de importantes autovías autonómicas cuya construcción está ya en marcha, al tiempo que se comenzarían las obras para construir otras nuevas en el marco de un plan de infraestructuras viarias que hasta el año 2010 pretende actuar sobre un total de 2.500 kilómetros de la red andaluza de carreteras. Asimismo, el candidato manifestó la necesidad de consolidar los grandes núcleos metropolitanos en Andalucía mediante la aprobación de los correspondientes instrumentos de ordenación territorial, que habrán de complementarse con medidas dirigidas a dotar las necesidades de la población en materia de transporte y gestión del agua. En este sentido se inscriben iniciativas ya en marcha como los metros de Granada, Málaga y Sevilla, el tren tranvía de la bahía de Cádiz o el proyecto de corredor ferroviario en la Costa del Sol.

En relación con un tema estrechamente relacionado con el anterior, la protección medioambiental, el candidato anunció la creación de "puertas verdes" en las ciudades mayores de 50.000 habitantes, que serán "puntos de partida hacia parques o enclaves protegidos con los que estarán conectados mediante vías verdes de uso exclusivo para senderistas y ciclistas". También está previsto que todos los municipios de 10.000 habitantes cuenten con un parque peri urbano, y que las industrias andaluzas se adapten a los parámetros ambientales contemplados en el Protocolo de Kyoto. Asimismo se anunció la aprobación de un Plan de Acción para la Estrategia Andaluza del Cambio Climático y la creación de la Agencia Andaluza de la Energía.

En materia de Administración Autonómica, el candidato se comprometió a aprobar "cartas de servicio" para todos los Departamentos y organismos de la Junta de Andalucía que tendrán por objetivo que el ciudadano conozca con claridad las prestaciones y los estándares de calidad a que tiene derecho. Además mostró su intención de que el establecimiento de la Administración electrónica crezca hasta alcanzar el $75 \%$ de los procedimientos administrativos. 
En el capítulo social, el candidato anunció la próxima puesta en marcha de un plan para incrementar los servicios públicos en las zonas andaluzas en las que se produce una mayor acogida de inmigrantes. La conquista de mayores niveles de bienestar pasa -en palabras del candidato- "por el reconocimiento de nuevos derechos sociales". Entre éstos, el Presidente en funciones se refirió a la creación de plazas en guardería para familias trabajadoras con hijos menores de tres años; la tele asistencia para mayores de 65 años que lo precisen; el chequeo médico anual para mayores; las plazas de educación infantil; el derecho a la gratuidad del dentista de cabecera para niños de 6 a 14 años; o el asesoramiento genético para la elección del sexo de los hijos en casos de enfermedades graves de carácter hereditario ligado al sexo. La integración y plena igualación de la mujer en el mercado laboral fue uno de los temas más desarrollados de este apartado dedicado al desarrollo del Estado social. En este campo, el objetivo confesado por el candidato es que "en un plazo de ocho años la tasa de actividad de las mujeres andaluzas se equipare a la media de la zona euro". Esta lucha por la igualdad se verá acompañada de medidas para evitar la discriminación en el ámbito laboral y de la aprobación de un proyecto de Ley contra la violencia de género. En el marco de las medidas socio-educativas, el candidato anunció el aumento de la dotación de ordenadores en los centros educativos públicos y la construcción de una plataforma digital de conocimientos que posibilite la educación digital, así como la existencia a finales de la legislatura de 400 centros educativos bilingües inglés-español. El candidato se refirió también a la integración de los discapacitados en el sistema educativo y laboral. En este último sentido, la Junta de Andalucía pretende reservar el $5 \%$ del empleo público, del que un $1 \%$ se dirigirá específicamente a los disminuidos psíquicos. La accesibilidad, el fomento de la lengua de signos o el subtitulado y audio descripción serán otras prioridades en este apartado. Por otra parte, el candidato anunció su intención de que la Junta de Andalucía mantenga las ayudas complementarias a las pensiones más reducidas, a la vez que establecerá nuevos derechos en materia de salud para garantizar mejores prestaciones. Esta larga lista de actuaciones en materia social se plasmará con la creación de la Consejería para la Igualdad y el Bienestar Social.

Por último, en el ámbito de la acción exterior de la Comunidad Autónoma, el candidato avanzó la creación del Consejo Andaluz de Cooperación, la aprobación de un plan específico y la creación de la Agencia Andaluza de Cooperación Internacional que permitan hacer del Mediterráneo y la integración europea los ejes principales de actuación en este campo.

La intervención del candidato a la Presidencia de la Junta de Andalucía fue seguida de las correspondientes réplicas a cargo de los Portavoces de los 
distintos Grupos Parlamentarios, que tuvieron lugar en la sesión de 21 de abril.

En primer lugar, el Portavoz del Grupo andalucista, D. Antonio Ortega, planteó una serie de reivindicaciones relacionadas con infraestructuras, como el traspaso de competencias sobre puertos y aeropuertos o la cuenca hidrográfica del Guadalquivir. Asimismo, instó al Presidente en funciones a que no implantase la ecotasa en el sector turístico, al tiempo que echó de menos en el discurso de investidura mayores referencias al Pacto local y al papel de los Ayuntamientos. El candidato contestó arguyendo que Andalucía ha sido en los últimos años la Comunidad líder en cooperación con los municipios, y avanzó -en este orden de argumentos- un inminente encuentro con el Presidente de la Federación Andaluza de Municipios y Provincias. Respecto a las exigencias del PA sobre competencias, el candidato recordó que ciertas parcelas de las mencionadas por el Portavoz del Grupo Andalucista eran de la exclusiva competencia del Estado, al tiempo que recordó el avance de las negociaciones sobre los traspasos pendientes en otras. Finalmente, el Presidente Chaves expresó su compromiso al Portavoz del Grupo Andalucista en orden a evitar que "la modernización del sistema autonómico" comporte "privilegios ni desigualdades" entre Comunidades, en referencia a las posibles reformas estatutarias que muy probablemente se emprenderían durante esta legislatura.

El anuncio de la creación de Agencia Andaluza de Alquileres centró, en buena parte, la intervención de la Portavoz de IULV-CA, Dña. Concha Caballero Cubillo, que reprochó al candidato que la liquidación de la financiación autonómica del periodo 1997-2001 se cifre en 2.500 millones. Caballero exigió, a su vez, que el Estado pague a Andalucía la "deuda histórica" en su integridad. Al hilo de una amplia crítica al modo en que se había articulado la intervención internacional en la guerra de Irak, la Portavoz también apunto sugerencias dirigidas al desmantelamiento de las bases militares en suelo andaluz en las que existen dotaciones estadounidenses. Por lo demás, mostró su decepción porque la futura Consejería de Igualdad y Bienestar Social no sea exclusivamente de Igualdad. En su turno de contrarréplica, el Presidente Chaves matizó que, a su juicio, el concepto de igualdad no significa únicamente igualdad de género, sino que tiene una dimensión social mucho más amplia, que en buena medida entronca con el concepto de bienestar social. Respecto a la deuda histórica, el candidato señaló que el Gobierno de la Junta de Andalucía llevaría a esta cuestión al órgano adecuado: el Consejo de Política Fiscal y Financiera. D. Manuel Chaves puntualizó, además, que la cifra de $2.500 \mathrm{mi}-$ llones obedece a una negociación con el anterior Gobierno y que este importe fue una de sus promesas electorales durante la pasada campaña andaluza. 
Asimismo, rechazó la pretensión de la Portavoz de IUCA de exigir al Gobierno central la renegociación del acuerdo España - EEUU para desmantelar las bases militares estadounidenses en suelo andaluz, argumentando el respeto debido a los Acuerdos bilaterales que rigen la materia.

Por su parte, la Portavoz del Grupo parlamentario del Partido Popular, Dña. Teófila Martínez Saiz, comenzó su réplica ofreciendo la colaboración de su Grupo parlamentario al futuro Gobierno de Andalucía en todo lo relativo a "la defensa del bienestar de los andaluces y Andalucía". Para ello, propuso la celebración de pactos de legislatura en materias como el empleo, la convergencia europea, la creación de infraestructuras y el desarrollo industrial. Durante su intervención, Dña. Teófila Martínez anunció, asimismo, la participación del PP andaluz en la ponencia para la reforma del Estatuto y el apoyo a las medidas de reforma que respeten la Constitución. En su respuesta, D. Manuel Chaves valoró positivamente el hecho de que el Grupo popular se sumase al debate para la reforma estatutaria aceptando las condiciones ofrecidas en la anterior legislatura. Recordó los derechos de las Comunidades Autónomas a estas reformas en los términos que recogen los propios Estatutos y la Constitución. Igualmente, el Presidente Chaves aprovechó su contrarréplica a la Portavoz del grupo popular para afirmar que hay una convergencia real de Andalucía con respecto a España y Europa. Según sus propias palabras, la Comunidad andaluza "tiene menos paro y más crecimiento económico, no sólo en las fases alcistas del ciclo económico sino en fases de ralentización”, donde crece por encima de la media nacional y europea”. Si bien resaltó la necesidad de acelerar ese proceso incentivando la participación y la inversión privada en $\mathrm{I}+\mathrm{D}-$ que actualmente no supera el $0,2 \%$ del PIB, de la que el $60 \%$ procede de capital público-. El candidato a la Presidencia declaró que el objetivo del Gobierno en esta legislatura es superar el $1 \%$ del gasto.

Finalmente, en su turno de palabra, D. José Caballos Mojeda, Portavoz del Grupo socialista, alabó el discurso de investidura del candidato, incidiendo en la importancia de algunos de los aspectos abordados en el mismo, como la Segunda modernización y la reforma estatutaria, y mostrando el total apoyo del Grupo socialista al futuro Gobierno, no sólo en los contenidos programáticos expuestos, sino también en el método de diálogo propuesto para alcanzarlos.

\section{Otros Debates generales}

Aparte del de investidura, se celebraron dos debates generales más, ambos instados por todos los Grupos Parlamentarios: Uno sobre el futuro de los astilleros andaluces, ante la propuesta realizada por el Gobierno de España de 
cierre y privatización de los mismos (sesión plenaria de 6 de octubre), y otro sobre las repercusiones para Andalucía del Proyecto de Ley de Presupuestos Generales del Estado para el año 2005 (sesión plenaria de 20 de octubre).

2. Proposiciones no de Ley.

Dejamos constancia a continuación de los temas sobre los que versaron dichas Proposiciones, que pueden dar cabal idea de los asuntos que durante el año merecieron la atención del Pleno de la Cámara.

- del Grupo Parlamentario Socialista: Proposición no de Ley relativa a siniestralidad laboral; sobre el eje ferroviario transversal de Andalucía; sobre la aplicación de la Ley Orgánica de Calidad de la Educación (LOCE); relativa al acuerdo en materia de financiación; sobre el apoyo al Plan de Actuaciones Hidráulicas del Gobierno de España; sobre las medidas para fomentar los valores educativos en televisión; relativa a España en la Constitución Europea; sobre gratuidad de los libros de texto; relativa a garantizar los principios de estabilidad y neutralidad presupuestarias en el régimen de pago único establecido en la reforma de la Política Agraria Comunitaria; relativa a la participación de las Administraciones en la financiación de los metros andaluces; sobre las medidas para la aplicación de la Ley Integral contra la Violencia de Género; relativa a las medidas para mejorar la convivencia en los centros escolares; sobre las medidas dirigidas a controlar el incremento de precios del gasóleo para los sectores agrario y pesquero, y paliar sus efectos; sobre protección de los consumidores ante el sobreendeudamiento; relativa a la incorporación de las tecnologías de la información y la comunicación (TIC) al proceso de aprendizaje universitario; referente a la elaboración de un marco legal para fomentar el autoempleo en Andalucía; sobre el cumplimiento de obligaciones en las infraestructuras andaluzas; relativa a la propuesta de aplicación de la reforma de la Organización Común de Mercado del aceite de oliva; y sobre el apoyo al Tratado de la Constitución Europea.

- del Grupo Parlamentario Popular: Proposición no de Ley relativa a medidas a adoptar ante los perjuicios de las reformas de las OCM de los sectores del aceite de oliva, algodón y tabaco para los agricultores andaluces; sobre una OCM justa y equilibrada para el olivar; relativa a la transparencia y control en la distribución de 2.500 millones de euros procedentes de la liquidación del sistema de financiación destinados a inversión; relativa a las selecciones deportivas autonómicas; relativa al cumplimiento del Plan Hidrológico Nacional en Andalucía; relativa al plan de actuación urgen- 
te para las zonas de Huelva y Sevilla afectadas por la catástrofe ocasionada por el incendio; sobre la suspensión de programas de fomento de empleo; relativa a la rectificación de la Ministra de Medio Ambiente sobre el modelo turístico en Andalucía; sobre la deuda histórica; sobre financiación de los metros andaluces; relativa a las medidas a adoptar frente a la subida del gasóleo, por las graves repercusiones económicas para los sectores productivos agrícolas, ganaderos y pesqueros de Andalucía; relativa al "agua para todos"; relativa a la adopción de medidas eficaces contra la violencia escolar; y sobre el acceso de los discapacitados al empleo en las Administraciones públicas;

- del Grupo Parlamentario Izquierda Unida Los Verdes-Convocatoria por Andalucía: Proposición no de Ley relativa a la restitución y mejora de los derechos y la cobertura social de los trabajadores del medio rural andaluz; referente a la investigación de la actuación de diversos organismos con ocasión del naufragio de una patera de inmigrantes el pasado 25 de octubre de 2003 en la bahía de Cádiz y sobre la situación de los recursos para salvamento marítimo en las costas andaluzas; relativa al derecho a la autodeterminación del pueblo saharaui; y sobre creación de la policía autonómica.

- del Grupo Parlamentario Andalucista: Proposición no de Ley relativa a la línea Ave Sevilla-Córdoba-Madrid; y sobre al pago por el Gobierno central de la liquidación contemplada en la Disposición Adicional Segunda del Estatuto de Autonomía de Andalucía -Deuda histórica-.

\section{Interpelaciones}

- del Grupo Parlamentario Popular: relativa a política general en materia de relaciones financieras con otras Administraciones; sobre política general en materia de carreteras; sobre política general en materia de políticas migratorias; sobre política general en materia de energía; sobre política general en materia de infraestructuras para la educación; sobre política general en materia de justicia; y sobre política general en materia de financiación, planificación e infraestructuras sanitarias.

- del Grupo Parlamentario Izquierda Unida Los Verdes-Convocatoria por Andalucía: relativa a política de empleo; sobre educación obligatoria y gratuita; y sobre política de inmigración.

- del Grupo Andalucista: relativa a política en materia de espectáculos públicos y legislación taurina.

Todas las interpelaciones se convirtieron posteriormente en mociones. 


\section{Mociones}

- del Grupo Popular. sobre relaciones financieras con otras Administraciones; sobre política general en materia de carreteras; sobre política general en materia de políticas migratorias; sobre política general en materia de energía; sobre política general en materia de infraestructuras para la educación; sobre política general en materia de justicia; y sobre política general en materia de financiación, planificación e infraestructuras sanitarias.

- del Grupo Parlamentario Izquierda Unida Los Verdes-Convocatoria por Andalucía: relativa a política de empleo; sobre educación obligatoria y gratuita; y sobre política de inmigración.

- del Grupo Andalucista: relativa a política en materia de espectáculos públicos y legislación taurina.

\section{Comparecencias ante el Pleno}

Se produjeron durante el año algunas comparecencias del Gobierno, o de alguno de sus miembros, ante el Pleno, la mas destacada de las cuales fue la del Consejo de Gobierno, a petición de los Grupos Parlamentarios de Izquierda Unida y Andalucista, a fin de explicar el acuerdo alcanzado con el Gobierno central respecto a la liquidación de la deuda acumulada en el periodo 1997-2001 y la transferencia de competencias. Asimismo son de destacar cuatro comparecencias más del Consejo de Gobierno, todas ellas instadas por el Grupo Parlamentario Popular, relativas, en primer lugar, a la posición del Gobierno andaluz ante el cierre y la privatización de los astilleros andaluces; en segundo lugar, a las consecuencias que para el empleo en esta Comunidad Autónoma se derivan de la Orden de 22 de julio por la que se suspenden diversos programas de fomento del empleo; en tercer lugar, al nuevo organigrama del Instituto de Fomento de Andalucía; y, finalmente, al balance sobre los primeros seis meses de gobierno. Ésta última fue bastante resonada, pues vino a hacer las veces del "debate sobre el estado de la Comunidad" que no fue celebrado este año. El resto de comparecencias fue realizada por los titulares de las Consejerías de Presidencia (2); Agricultura y Pesca (5); Gobernación (1); Salud (1); Empleo (4); Medio Ambiente (4); Educación (3); Innovación, Ciencia y Empresa (4).

\section{Preguntas al Gobierno:}

Preguntas de iniciativa ciudadana en Comisión: 2; Preguntas escritas al Gobierno: 2.070; Preguntas orales en Comisión: 472; Preguntas orales en pleno: 347 


\section{Gobierno}

Un mes antes de las elecciones, concretamente el 10 de febrero, el Presidente Chaves tuvo que remodelar el Consejo de Gobierno por figurar cuatro de sus Consejeros como candidatos en las listas para el Congreso de los Diputados, sonando estos cuatro nombres como "ministrables" en caso de alzarse con la victoria electoral el Sr. Rodríguez Zapatero. Fueron los titulares de las Consejerías de Economía y Hacienda (Magdalena Álvarez Yarza), Justicia y Administración Pública ( $M^{\mathrm{a}}$ del Carmen Hermosín Bono), Cultura (Carmen Calvo Poyato) y Gobernación (Alfonso Perales Pizarro), que fueron sustituidos por los Viceconsejeros de las respectivas Consejerías.

Tras su quinta victoria electoral en Andalucía el Sr. Chaves así como su nuevo Gobierno tomaron posesión de sus cargos el 25 de abril. Fiel a su compromiso de implantar la paridad de género en todos los órganos colegiados lo cumplió con creces al formar el Gabinete al nombrando a ocho mujeres como titulares de las Consejerías, de las catorce existentes. Repitieron como titulares de Consejerías siete miembros del Gobierno anterior.

No cambió el número de Consejerías pero sí su estructura y denominación. Entre las modificaciones destaca la supresión de la Consejería de Relaciones Institucionales, antes en posesión del Partido Andalucista durante la etapa de la coalición, y la creación de una especie de súper consejería -Innovación, Ciencia y Empresa- que llega a asumir competencias antes en manos de hasta cinco Consejerías. Entre otras materias asume todo lo concerniente a la educación e investigación universitarias, rama que se escinde así de la Consejería de Educación en la que se encontraba desde su origen. Esta nueva macro Consejería se configura como abanderada para propulsar las acciones de la llamada Segunda modernización que es el programa que se pretende guíe la acción política y administrativa.

\section{Ejercicio de las competencias}

A nivel normativo, el ejercicio de las competencias mediante reglamentos ha disminuido en cuanto a su número respecto al de años pasados, lo que resulta normal tratándose de un año electoral.

Entre las disposiciones organizativas, destaca el Decreto 11/2004 por el que se reestructuran las Consejerías. Asimismo, la remodelación de la Comisión Delegada de Asuntos Económicos y la creación de la Comisión de Política Económica, acorde con la nueva estructura de las Consejerías (D. 480/2004), así como una modificación de la norma reguladora de las Delega- 
ciones del Gobierno cuyo fin es el dar participación a la Consejería de la Presidencia en el nombramiento de los titulares de estos órganos (D. 117/2004). Por su parte, el Decreto 557/2004 crea la Comisión Interdepartamental de Acción Exterior, que sustituye así a la anterior Comisión de Asuntos Europeos y Cooperación Exterior.

Un Decreto impulsado por la Consejería de Presidencia regula el informe que ha de preceder a los proyectos de Ley y de Reglamentos para evaluar el "impacto de género" (D. 93/2004), y la misma Consejería promueve el Decreto 521/2004 de 9 de noviembre por el que se crea la Comisión Interdepartamental para el reconocimiento de las víctimas de la Guerra civil y del franquismo, que ha de dedicarse a la formación de un centro documental al respecto, así como proponer medidas para el reconocimiento social y la reparación moral de los daños causados a las víctimas.

Por último, es de citar el D. 95/2004 por el que se crea el Consejo Andaluz de Medicina Legal y Forense y la Comisión de Coordinación de los Institutos de Medicina Legal de Andalucía, entidades estas en las que se han integrado los profesionales de los antiguos Institutos Anatómico-Forenses y de las clínicas forenses de los juzgados. El Consejo que se crea integra a los distintos Institutos Provinciales y se constituye como órgano consultivo de la Administración de Justicia.

En el ámbito de la función pública, se modifica parcialmente el Reglamento general de ingreso, provisión de puestos de trabajo y promoción profesional e interna de los funcionarios de la Administración General de la Junta, al objeto de incluir diversas mejoras pactadas con los sindicatos en materias de reserva de plazas para discapacitados, Administración electrónica, regulación de la movilidad y reordenación y simplificación de los trámites de provisión de puestos de trabajo (D. 528/2004).

En cuanto al régimen local, el D. 365/2003 establece el régimen transitorio de las televisiones locales por ondas terrestres, al objeto de paliar la inseguridad producida por el retraso en la aplicación de la Ley estatal de 1995 y cubrir así la situación de muchas televisiones locales que funcionan sin título habilitante.

En el ámbito de la ordenación del territorio, el D. 462/2004 aprueba el Plan de Ordenación del Territorio de la Bahía de Cádiz y crea su Comisión de Seguimiento. El Plan afecta a los municipios de Cádiz, Chiclana de la Frontera, El Puerto de Santa María, Puerto Real y San Fernando. El Plan prevé unas inversiones de unos 1.300 millones de euros para mejora de infraestructuras. 
En materia de urbanismo, aunque no exclusivo de este sector, hay que dar cuenta del Reglamento de Organización y Funcionamiento de las Comisiones Provinciales de Valoraciones (D. 85/2004), dictado en desarrollo de la Ley de Ordenación Urbanística de Andalucía, que habrán de fijar el justiprecio en las expropiaciones en las que intervenga la Junta de Andalucía o las entidades locales de la Comunidad Autónoma. También en cumplimiento de dicha Ley urbanística el Decreto 2/2004 regula los registros de instrumentos de planeamiento, de convenios urbanísticos y de los bienes y espacios catalogados, creando el Registro autonómico, todo ello en pro de la publicidad y posibilidad de consulta por parte de los ciudadanos.

En el sector vivienda, hay que registrar la modificación del Plan Andaluz de Vivienda y Suelo 2003-2007 mediante el Decreto 463/2004, al objeto de adaptarlo a las medidas aprobadas por el Gobierno central en julio de 2004; y el Reglamento para la Acreditación y Registro de las entidades de control de calidad de la construcción (D. 448/2004).

En las áreas de agricultura y pesca, el D. 448/2004 complementa las ayudas estatales destinadas a proyectos de modernización de zonas regables declaradas de interés general por el Plan Nacional de Regadíos. Por su parte, el D. 84/2004 aprueba el Reglamento de Cofradías de Pescadores y sus Federaciones, que afecta a las 23 Cofradías que existen de los 25 puertos pesqueros andaluces y que a su vez se agrupan en Federaciones sitas en las provincias costeras andaluzas.

En materia de industria hay que registrar la aprobación del Plan Industrial para Andalucía 2003-2006 (D. 323/2003); y el D. 441/2004 sobre régimen económico de los costes del suministro de gases combustibles por canalización, con el fin de homogeneizarlos para todo el territorio andaluz.

En el área de consumo el D. 537/2004 regula los derechos de consumidores y usuarios en el ámbito de la venta al por menor y suministro de productos petrolíferos; y el D. 103/2004 atribuye competencias sancionadoras en la materia a distintos órganos de la Administración autonómica.

En el ramo de medio ambiente el D. 99/2004 aprueba la revisión del Plan de Gestión de Residuos Peligrosos de Andalucía, sustituyendo al anterior de 1998, siendo su objetivo la reducción de la producción total de residuos peligrosos entre un 10 y un 15 por ciento antes de 2010. Por su parte, el D. 503/2004 regula determinados aspectos para la aplicación de los Impuestos sobre emisión de gases a la atmósfera y sobre vertidos a las aguas litorales, "im- 
puestos ecológicos" que fueron contemplados en la Ley de acompañamiento de finales de 2003.

$\mathrm{Al}$ igual que en el ejercicio anterior, hay que dar cuenta de una serie de Decretos -todos ellos anteriores a las elecciones del 14 de marzo- aprobatorios de Planes de Ordenación de Recursos Naturales y de sus correspondientes Planes Rectores de Uso y Gestión; así los del Parque Natural Sierra de las Nieves, Málaga (D. 344/2003), Sierra de Andujar, Jaén (354/2003), Sierras Subbéticas, Córdoba (4/2004), Despeñaperros (56/2004), Sierra Mágina, Jaén (57/2004), Sierra Norte de Sevilla (80/2004), Los Alcornocales, Cádiz (87/2004), Sierras de Huétor, Granada (100/2004), Sierra de Baza, Granada (101/2004). Debe destacarse la aprobación (D. 48/2004) del PRUG del Parque Nacional de Doñana, espacio considerado por la Unesco como Patrimonio de la Humanidad y Reserva de la Biosfera, y que ocupa 50.720 hectáreas de marismas, dunas, pinares, alcornocales y monte mediterráneo ubicadas en las Provincias de Huelva y Sevilla, aunque su área de influencia o "preparque" abarca hasta 55.327 hectáreas). El Parque constituye hoy el último reducto virgen de las casi 200.000 hectáreas que hace tres siglos componían el área inundable del Bajo Guadalquivir. Doñana sirve de refugio a las principales especies de la fauna ibérica en peligro de extinción, entre ellas el lince ibérico, el águila imperial, la malvasía y la focha cornuda. Tres grandes ecosistemas conforman el Parque Nacional de Doñana: la marisma, terreno inundado durante la época invernal que acoge más de 300 especies diferentes de aves; las dunas móviles, situadas en una franja litoral de casi 40 kilómetros de longitud entre la desembocadura del río Guadalquivir y Matalascañas, y los pinares y cotos de monte mediterráneo, donde sobreviven ejemplares de pino piñonero de hasta 300 años de antigüedad. El nuevo centra sus prioridades en reforzar la protección de la biodiversidad, garantizar la integridad de los ecosistemas, ampliar sustancialmente la oferta de uso público y mejorar la regulación del tránsito rociero y de los aprovechamientos ligados a la ganadería, el marisqueo, la apicultura y la recogida de piñas. Entre sus distintas medidas y propuestas, el Plan delimita por primera vez la división de las 50.720 hectáreas que componen su ámbito de acuerdo con sus distintos valores ecológicos. Se determinan así cuatro zonas, de las cuales las de reserva o máxima protección abarcan el $25 \%$ del territorio.

Sobre la materia de empleo es destacable la aprobación del Plan General para la Prevención de Riesgos Laborales en Andalucía (D. 313/2003), cumplimentando así una de las previsiones del V acuerdo de concertación social adoptado en 2003. 
En el área de salud el D. 96/2004 establece la garantía de plazo de respuesta en procesos asistenciales, primeras consultas de asistencia especializada y diagnósticos en el sistema público de salud. Con esta norma se pretende reducir progresivamente las listas de espera en la atención sanitaria especializada. Entre otras previsiones, el objetivo es que ningún paciente tenga que esperar más de 60 días para ser atendido en la consulta del especialista ni más de 30 para realizarse una prueba diagnóstica. En caso de que se superen estos plazos los pacientes tendrán derecho a acudir a un centro privado con cargo a la Junta de Andalucía. Por otro lado, el D. 238/2004 regula el Registro de Voluntades Vitales Anticipadas, para hacer efectivo el derecho a decidir sobre la asistencia sanitaria y los tratamientos médicos que desean recibir los enfermos en situaciones graves o irreversibles.

En este mismo sector hay que destacar el D. 353/2003 que establece la planificación farmacéutica y los procedimientos de autorización de oficinas de farmacia. Esta regulación permite a la Administración impulsar de oficio concursos públicos para la implantación de farmacias en áreas o situaciones deficitarias de este servicio.

En materia de educación se modifica la norma sobre los Consejos Escolares de los Centros docentes públicos y de los Privados concertados, para adaptarlos a la LOCE.

En el campo de la asistencia social, hay que reseñar la aprobación (D. 362/2003) del Plan Integral de Atención a la Infancia (2003-2007); y otra disposición complementaria: el D. 3/2004 que establece el sistema de información sobre maltrato infantil, estableciendo deberes de denuncia por parte de particulares y de coordinación administrativa. Del mismo corte que el anterior es el D. 23/2004 regulador de la protección jurídica de las personas mayores. Dentro de este apartado también cabe referir el D. 7/2004 sobre ampliación de las medidas de apoyo a las familias andaluzas con el fin de facilitar el acceso a las ayudas para guarderías, mejora de viviendas de personas mayores y adquisición de libros de texto.

En el área de turismo, el D. 340/2003 aprueba el Plan General de Turismo de Andalucía que prevé importantes inversiones para el fomento de este sector estratégico en esta Comunidad. Por su parte, el D. 47/2004 regula las condiciones técnicas y servicios de los establecimientos hoteleros, introduciendo nuevos criterios de distinción entre clases y modalidades de establecimientos. Por otro lado, el D. 15/2004 de 27 de enero regula las declaraciones de interés turístico de Andalucía, estableciendo tres clases de declaraciones 
posibles: fiestas y acontecimientos, itinerarios turísticos y publicaciones y obras audiovisuales.

Por último, en materia de deporte el D. 55/2004 aprueba el Reglamento del Voluntariado Deportivo en Andalucía para promover la participación de voluntarios en los eventos deportivos.

\section{Conflictividad}

Hay que registrar la aparición de la STC 194/2004 de 15 de noviembre por su especial incidencia en Andalucía, tanto por contar con dos Parques Nacionales de la importancia del de Doñana y Sierra Nevada como por ser esta Comunidad y la de Aragón las recurrentes de la Ley estatal 41/1997 que fijó las competencias en materia de Parques Nacionales tras la aparición de la STC 102/1995, especialmente ambigua en el punto controvertido. El nuevo criterio del TC es el de la competencia exclusiva (no conjunta) de la Comunidad Autónoma en la gestión de los Parques Nacionales, amén de otros pronunciamientos (proscribiendo la función ejecutiva de los Patronatos, o el nombramiento por el Gobierno del Director-conservador, o la aprobación por el Gobierno del Plan Rector de Uso y Gestión) que establecen el deslinde competencial entre el Estado y las Comunidades Autónomas en este sector, volcando las competencias de ejecución en la Comunidad Autónoma. Un pronunciamiento importante, también a efectos generales.

Las controversias planteadas ante el Tribunal Constitucional en año 2004 -todas ellas anteriores a las elecciones del 14 de marzo- fueron las siguientes:

Promovidas por la Junta de Andalucía:

- Recurso de Inconstitucionalidad número 632-2004, promovido por el Parlamento de Andalucía, en relación con diversos preceptos de la Ley $45 / 2003$, de 21 de noviembre, por la que se modifica la Ley 35/1988, de 22 de noviembre, sobre Técnicas de Reproducción Asistida, recurso que fue apoyado por todos los Grupos parlamentarios, a excepción del Partido Popular. Este recurso viene a ser la réplica al promovido por el Presidente del Gobierno (número 7552-2003) contra la Ley 7/2003, de 20 de octubre, del Parlamento de Andalucía, por la que se regula la investigación en Andalucía con preembriones humanos no viables para la fecundación in vitro, recurso este que fue interpuesto a finales de 2003, aunque su aparición en los diarios oficiales se produjera a comienzos de 2004. En el Informe del ejercicio de 2003 ya dejamos constancia de esta controver- 
sia que versa sobre la delimitación de competencias sobre investigación científica y técnica y de sanidad, uno de los asuntos más enconados que enfrentó a la Junta de Andalucía y al Gobierno del Partido Popular en la etapa final de la legislatura regida por el Presidente Sr. Aznar.

- Recurso de inconstitucionalidad número 1083-2004, promovido por el Consejo de Gobierno de la Junta de Andalucía contra determinados preceptos de la Ley 45/2003, de 21 de noviembre, sobre Técnicas de Reproducción Asistida (ver recurso citado anteriormente).

- Recurso de inconstitucionalidad número 1014-2004, promovido por el Consejo de Gobierno de la Comunidad Autónoma de Andalucía, en relación con determinados preceptos de la Ley 43/2003, de 21 de noviembre, de Montes, por entender que tres de sus preceptos vulneran competencias medioambientales de la Junta de Andalucía.

- Recurso de inconstitucionalidad núm. 1648-2004, promovido por el Consejo de Gobierno de la Junta de Andalucía contra el art. 92 y correspondiente partida presupuestaria de la Sección 32 de la Ley 61/2003, de 30 de diciembre, de Presupuestos Generales del Estado para el año 2004, relativo a la evaluación de las entregas a cuenta del Fondo de Suficiencia destinado a corregir los desequilibrios entre Comunidades como consecuencia de la aplicación del módulo de financiación autonómica.

- Recurso de inconstitucionalidad número 2004-2004, promovido por el Consejo de Gobierno de la Junta de Andalucía contra los artículos 126, 127 y 129 de la Ley 62/2003, de 30 de diciembre, de Medidas Fiscales, Administrativas y del Orden Social, concretamente en materia de demarcaciones hidrográficas (imposibilitando así la transferencia de la competencia), espacios naturales y evaluación de impacto ambiental.

- Conflicto positivo de competencia núm. 145-2004, promovido por el Consejo de Gobierno de la Junta de Andalucía, en relación con determinados preceptos del Real Decreto 1046/2003, de 1 de agosto, por el que se regula el Subsistema de Formación Profesional Continua.

- Conflicto positivo de competencia núm. 2587-2004, promovido por Consejo de Gobierno de la Junta de Andalucía, en relación con la disposición adicional quinta del Real Decreto 176/04, de 30 de enero, por el que se aprueba el Estatuto del Centro Nacional de Trasplantes y Medicina Regenerativa, y contra los arts. 5.b), 1. $.^{-}, 2 .^{-}, 4 .^{-}, 5 .{ }^{-}$y 12.2 del referido Estatuto. 
Promovidas por el Estado:

- Recurso de inconstitucionalidad núm. 1022-2004, promovido por el Presidente del Gobierno, en relación con determinados preceptos de la Ley 10/2003, de 6 de noviembre, reguladora de los Colegios profesionales de Andalucía. Por auto de 11 de mayo de 2004 el TC levantó la suspensión de dicha Ley, aquietándose el Abogado del Estado. Esta Ley regula la libre colegiación de los funcionarios que trabajan en exclusiva para la Administración (art. 4), asunto este que ya comentamos en el informe del pasado año.

- Recurso de inconstitucionalidad núm. 2102-2004, promovido por Presidente del Gobierno contra determinados preceptos de la Ley del Parlamento de Andalucía 18/2003, de 29 de diciembre, por la que se aprueban medidas fiscales y administrativas. Impugna lo relativo al impuesto sobre depósitos de residuos radiactivos por entender que traspasa los límites de la potestad tributaria autonómica. Se trata de uno de los cuatro "impuestos ecológicos" que fueron tan apoyados por el Grupo de Izquierda UnidaLos Verdes en la legislatura anterior.

Por otra parte algunos juzgados de Córdoba han planteado cuestiones de inconstitucionalidad sobre el controvertido tema de las Cajas de Ahorro, concretamente sobre la incidencia que tuvo sobre la cordobesa Cajasur, regida por la Iglesia católica, la Disposición adicional 5 $5^{\mathrm{a}}$ de la Ley de Andalucía 10/2002, de 21 de diciembre, por la que se aprueban normas en materia de tributos cedidos y otras medidas tributarias, administrativas y financieras, por supuesta vulneración del art. 9.3 de la Constitución; y sobre el art. 8, apartado 15, de la Ley 44/2002, de 22 de noviembre, de Medidas de Reforma del Sistema Financiero, que modifica la Disposición Adicional Segunda de la Ley 31/1985, de 2 de agosto, de Regulación de las Normas Básicas sobre Órganos Rectores de las Cajas de Ahorros, por presunta vulneración de los arts. 149.1.11. a y 149.3 de la Constitución, en relación con el art. 18.1.3. ${ }^{\text {a }}$ del Estatuto de Autonomía de Andalucía. Tales han sido las cuestiones de inconstitucionalidad números 5094-2003, admitida a trámite por providencia del TC de 24 de febrero de 2004, que plantea el Juzgado de Primera Instancia número Uno; 6250-2003, admitida a trámite el 25 de mayo de 2004, Juzgado de Primera Instancia núm. 4; y 1381-2004, admitida a trámite el 7 de junio de 2004, Juzgado de Primera Instancia núm. 6.

\section{Desistimientos ante el Tribunal Constitucional.}

En esta ocasión hemos de abrir un apartado -paradójicamente en este epígrafe dedicado a la conflictividad- para dejar constancia de los desisti- 
mientos instados ante el TC por el Estado y la Junta de Andalucía tras la pactación habida entre ambas partes tras las elecciones del 14 de marzo.

Instados por la Junta de Andalucía:

Recurso de inconstitucionalidad núm. 1030-1999, planteado en relación con los artículos 3, 58, 59, 60, 61, 62, 63, 64, 65 y 81.5 y Disposición final cuarta de la Ley 40/1998, de 9 de diciembre, del Impuesto sobre la Renta de las Personas Físicas y Otras Normas Tributarias (Auto del Tribunal Constitucional de 21 de septiembre de 2004 por el que se acuerda el desistimiento).

Recurso de inconstitucionalidad número 1304-1999, interpuesto contra los artículos 82 a 87, 89 y 90 y las partidas de las Secciones 32 y 33 de la Ley 49/1998, de 30 de diciembre, de Presupuestos Generales del Estado para 1999, por los que se aprueban los porcentajes de participación de las Comunidades Autónomas en los ingresos del Estado para el quinquenio 1997-2001 y se distribuyen entre las Comunidades Autónomas los créditos correspondientes (Auto del Tribunal Constitucional de 14 de septiembre de 2004 por el que se acuerda el desistimiento).

Recurso de inconstitucionalidad número 1358/1999, manteniéndose únicamente la impugnación del artículo 86 y de las cuantías fijadas en la Sección 32: "Dirección General de Coordinación con las Haciendas Territoriales", "Participación de las Comunidades Autónomas en los ingresos del Estado-Programa 911 B", de la Ley 49/1998. (Auto del Tribunal Constitucional de 19 de octubre de 2004 por el que se acuerda el desistimiento parcial solicitado).

Recurso de inconstitucionalidad núm. 1828-2000 planteado en relación con los artículos 87, 88, 89, 90, 91, 93 y 94 y correspondientes partidas presupuestarias, de la Ley 54/1999, de 29 de diciembre, de Presupuestos Generales del Estado para el año 2000 (Auto del Tribunal Constitucional de 21 de septiembre de 2004 acordando el desistimiento).

Recurso de inconstitucionalidad núm. 1245-2001 promovido contra artículos $79,80,81,82,83,84,85$ y 86 de la Ley 13/2000, de 28 de diciembre, de Presupuestos Generales del Estado para el año 2001, así como con relación a determinadas partidas presupuestarias de las Secciones 32 y 33 de dichos Presupuestos. (Auto del Tribunal Constitucional de 5 de octubre de 2004 por el que se acuerda el desistimiento). 
Recurso de inconstitucionalidad número 1903-2002, (desistimiento parcial) planteado en su día contra los artículos 84,86 y 88 y las correspondientes partidas presupuestarias de las Secciones 32 y 33 de la Ley 23/2001, de 27 de diciembre, de Presupuestos Generales del Estado para 2002. El desistimiento se produce en relación a la impugnación de los artículos 84, 86 y las correspondientes partidas presupuestarias de la Sección 32 de dicha Ley, manteniéndose el recurso respecto a la impugnación del artículo 88 y de las correspondientes partidas presupuestarias de la Sección 33. (Auto del Tribunal Constitucional de 14 de septiembre de 2004 por el que se acuerda el desistimiento).

Recurso de inconstitucionalidad número 1850-2003, en lo que se refiere a la impugnación del artículo 78 y correspondiente partida presupuestaria de la Ley 52/2002, de 30 de diciembre, de Presupuestos Generales del Estado para el año 2003. (Auto del Tribunal Constitucional de 21 de septiembre de 2004 por el que se acuerda el desistimiento parcial del recurso)

Instados por el Estado:

Conflicto positivo de competencia número 2446-1999, en relación con el Acuerdo de 29 de diciembre de 1998 de la Consejería de Medio Ambiente de la Junta de Andalucía por el que se aprueba la formulación del Plan de Ordenación de los Recursos Naturales de la Isla de Alborán (BOE núm. 240 de 5 de octubre). (Auto del Tribunal Constitucional de 14 de septiembre de 2004 por el que se acuerda el desistimiento).

Recurso de inconstitucionalidad número 7552/2003, promovido en su día por el Presidente del Gobierno contra la Ley 7/2003, de 20 de octubre, del Parlamento de Andalucía, por la que se regula la investigación en Andalucía con preembriones humanos no viables para la fecundación in vitro. (Auto del Tribunal Constitucional de 7 de junio de 2004 por el que se acuerda el desistimiento). 


\section{ACTIVIDAD INSTITUCIONAL}

Composición de la Asamblea Legislativa por Grupos Parlamentarios

Total Diputados: 109

Composición a 1-I-2004:

Socialista (PSOE-A): 52

Popular de Andalucía (PP-A): 46

Izquierda Unida Los Verdes-Convocatoria por Andalucía (IU-CA): 6

Andalucista (PA): 3

Grupo Mixto (integrado por 2 miembros del PSA, escindido del PA): 2

Composición a 31-XII-2004, como resultado de las elecciones autonómicas del 14 de marzo de 2004:

Socialista (PSOE-A): 61

Popular de Andalucía (PP-A): 37

Izquierda Unida Los Verdes-Convocatoria por Andalucía (IU-CA): 6

Andalucista (PA): 5

Estructura del Gobierno

Presidente: Manuel Chaves González

Número de Consejerías: 14

Presidencia: Gaspar Zarrías Arévalo

Gobernación: Evangelina Naranjo Márquez

Economía y Hacienda: José Antonio Griñán Martínez

Justicia y Administración Pública: María José López González

Innovación, Ciencia y Empresas: Francisco Vallejo Serrano

Obras Públicas y Transportes: Concepción Gutiérrez del Castillo

Empleo: Antonio Fernández García.

Turismo, Comercio y Deporte: Paulino Plata Cánovas

Agricultura y Pesca: Isaías Pérez Saldaña

Salud: María Jesús Montero Cuadrado

Educación y Ciencia: Cándida Martínez López

Igualdad y Bienestar Social: Micaela Navarro Garzón.

Cultura: Rosario Torres Ruiz

Medio Ambiente: Fuensanta Coves Botella

Tipo de Gobierno

Mayoritario absoluto. El partido Socialista ostenta 61 de los 109 escaños por lo que goza de una holgada posición mayoritaria, excediendo en seis los 
escaños necesarios para la mayoría absoluta. Ello hace innecesario el pacto de legislatura y de gobierno mantenido con el Partido Andalucista en la VI legislatura en la que este partido realizó el apoyo con sus tres escaños.

Cambios en el Gobierno: No ha habido

Investidura, moción de censura y cuestión de confianza: Investidura como Presidente de Don Manuel Chaves González en sesión del pleno del Parlamento celebrada los días 20 y 21 de abril de 2004. Nombrado por Real Decreto $743 / 2004$ de 23 de abril.

Mociones de reprobación: No ha habido

Debates y resoluciones parlamentarias.

Proposiciones no de Ley ante el Pleno: vid. supra.

Mociones sustanciadas en Pleno: 14

Comparecencias de miembros del Consejo de Gobierno ante el Pleno: 29

Interpelaciones a miembros del Consejo de Gobierno: 11

Reformas del Reglamento del Parlamento: Durante 2004 se ha venido debatiendo su reforma que posiblemente se producirá en 2005. Los aspectos fundamentales de la modificación son los relativos a Comisiones de investigación, control de empresas públicas, preguntas orales en el Pleno y calendario de sesiones.

\section{Consejo Consultivo de Andalucía.}

En el aspecto institucional cabe dejar constancia de que en este año de 2004, concretamente el día 18 de febrero, se cumplió el X aniversario de la constitución del Órgano. En estos diez años el Consejo ha emitido más de dos mil dictámenes. Grosso modo, los porcentajes de los tipos de asuntos más importantes han sido los siguientes en esta década: dictámenes previos a leyes y reglamentos, 16\%; revisión de oficio de actos, $17 \%$; en materia de contratación, 23\%; responsabilidad patrimonial, 37\%; modificación de zonas verdes y espacios libres, 9\%. Los dictámenes sobre asuntos tramitados por entidades locales pueden cifrarse en un $36 \%$ sobre el total.

Con retraso respecto a lo que ha venido siendo habitual, el día 3 de noviembre de 2004 el Consejo Consultivo presentó ante el Gobierno, en la ciudad de Granada, su Memoria anual correspondiente al año 2003.

Sobre los datos que arroja esa Memoria de 2003 ya hicimos un avance en esta misma crónica en el Informe del pasado año y como los datos son coincidentes nos remitimos a lo dicho allí. Centrándonos ya en la actividad del Con- 
sejo del año 2004 podemos avanzar, sin perjuicio de los datos definitivos que ofrezca la Memoria a presentar durante 2005, que se aprecia un descenso del número de dictámenes solicitados (460) -59 solicitudes menos- y admitidos a trámite (451) -40 admisiones menos-, lo que supone un cambio de signo respecto a la línea ascendente sostenida desde la creación de este órgano consultivo El número de dictámenes emitidos fue de 406, frente a los 464 del ejercicio anterior. De ellos, 308 fueron favorables a la propuesta de la Administración, siendo 98 los que se emitieron en sentido desfavorable; es decir, proporciones 76 y 24 por ciento, respectivamente. El número de dictámenes emitidos sobre solicitudes formuladas por entidades locales fue de 230, o sea, el 56 por ciento del total, lo que supone un notable incremento sobre ejercicios anteriores en que la media venía siendo de un tercio de los dictámenes emitidos. La cifra es aún más sorpresiva si se tiene en cuenta la importante limitación introducida por la Ley de acompañamiento de 2002 (6000 euros de cuantía mínima) para la admisión de los asuntos sobre responsabilidad patrimonial provenientes de entidades locales.

El desglose por asuntos principales es el siguiente: 3 dictámenes sobre $A n$ teproyectos de Ley y 23 sobre Proyectos de disposiciones reglamentarias, cifras muy reducidas respecto al ejercicio anterior, aunque consecuentes con el descenso de producción normativa ya comentado. Hay que registrar 4 solicitudes de dictámenes sobre recursos de inconstitucionalidad y 3 conflictos de competencia. Ha aumentado sobre el año anterior el número de revisiones de oficio (54); han disminuido ostensiblemente los asuntos sometidos a control en materia de contratación (43), y ha crecido llamativamente -más del doble- la cifra de los relativos a alteración por Planes urbanísticos de zonas verdes y espacios libres, dotaciones y equipamientos (71), lo que probablemente esté motivado por la ampliación de la preceptividad del dictamen en lo referido a las "dotaciones y equipamientos", operada por la Ley de Ordenación Urbanística de Andalucía $7 / 2002$. En cuanto a lo que ha venido siendo el grueso de la actividad consultiva, los asuntos de responsabilidad patrimonial, el número sigue elevándose (251) subiendo también aunque moderadamente los referidos a entidades locales (104).

Han sido 256 -el 63 por ciento- las resoluciones comunicadas al Consejo Consultivo por la Administración tras la emisión de los dictámenes, cifra que disminuye respecto a la del ejercicio anterior a pesar que el propio Consejo hace recordar cada año en sus Memorias que se trata de un deber legal. Tal comunicación post-dictamen es la que da a conocer si la resolución de que se trate se dicta "de conformidad" con el dictamen o simplemente "oído", por apartarse del mismo. Por cierto que el ejercicio registra un incremento nota- 
ble de asuntos (34) en que el Consejo ha sido "oído", pero como hemos dicho en otras ocasiones este dato no es significativo por sí mismo dado que no consta lo ocurrido con el resto de las resoluciones finales no comunicadas al Consejo, entre las que es lógico pensar que se encuentren en mayor medida las que desatienden el parecer del órgano consultivo.

Dentro del paquete de medidas llamadas "de impulso democrático" puestas en marcha tras el comienzo de la legislatura en marzo de 2004 figura la reforma del Consejo Consultivo. Así, en el Diario del Parlamento de 9 de diciembre aparece la proposición de ley, presentada por todos los Grupos excepto el Popular, para la tramitación directa y en lectura única ante el Pleno del nuevo texto legal llamado a sustituir la Ley 8/1993 de 19 de octubre. Se trata, pues, de un texto legal nuevo, no de una simple modificación del anterior a pesar de que las innovaciones que introduce son muy puntuales. Las más destacadas son la creación de la categoría del Consejero Permanente en la que podrán integrarse los ex Presidentes de la Junta de Andalucía; la composición paritaria en hombres y mujeres de sus miembros; la reducción a seis del número de consejeros electivos (son doce en la actualidad) con dedicación exclusiva y a tiempo completo y que son los que han de componer la Comisión Permanente. Se prevé la posibilidad de que ésta se subdivida en Secciones. También se contempla la posibilidad de que el Consejo de Gobierno pueda nombrar hasta seis consejeros más, sin dedicación exclusiva. Estos habrán de integrarse en el Pleno.

Con esta remodelación, la Comisión Permanente -eje de la instituciónresulta de los propios nombramientos del Consejo de Gobierno, perdiendo la presidencia del Organo el cierto poder de configuración que tiene en la actualidad. Por otra parte, no cabe soslayar la definición que el artículo $1^{\circ}$ hace del Consejo como "supremo órgano de asesoramiento-sic- de las Entidades Locales y de los Organismos y Entes de Derecho Público de ellas dependientes". Habrá que ver si del texto definitivo de la Ley resulta que el Consejo asume verdaderas funciones de asesoramiento -lo cual no casaría con la reducción de miembros operada en su Comisión Permanente-, o se trata en realidad de la función de control -que no de asesoramiento- que es la propia de estos Órganos y la que se realiza en la actualidad.

\section{Cámara de Cuentas.}

El Informe sobre la Cuenta general de la Junta de Andalucía del ejercicio 2002 fue presentada al Parlamento el 27 de junio. Destaca el Informe la deuda del Servicio Andaluz de Salud que ascendía a 1.800 millones de euros. 
La Cámara de Cuentas evacuó el primer Informe especial, en noviembre de 2004, sobre la fiscalización de los gastos electorales de las elecciones autonómicas al Parlamento de Andalucía de 2004. Respecto de la propuesta de subvención acordada para cada formación política, el Informe hace el siguiente desglose: El Partido Socialista Obrero Español ha contado para las Elecciones al Parlamento de Andalucía con 3.349.132,09 euros. Dicha formación ha declarado gastos por importe de 3.385.846,79 euros que, a juicio de la Cámara de Cuentas, están justificados. Por su parte, el Partido Popular ha contado con un total de 3.215.709,34 euros que también están justificados. Por lo que respecta a Izquierda Unida Los Verdes-Convocatoria por Andalucía, esta formación ha contado con 1.469.849,07 euros; pero del total de gastos declarados se detecta que existen gastos que, a juicio de la Cámara de Cuentas, no están debidamente justificados por un total de 14.297,61 euros. Finalmente, el Partido Andalucista ha contado para las Elecciones al Parlamento de Andalucía con 858.975,51 euros y ha declarado gastos por un importe de 856.849,09 euros. Asimismo, esta formación política, a pesar de presentarse a los Comicios Generales, declara no haber incurrido en gastos imputables a estas elecciones. No obstante, la Cámara de Cuentas considera que un $10 \%$ de los gastos declarados son imputables a las Elecciones a Cortes Generales (85.684,91 euros). De este modo, la cifra de gastos que considera imputables a las Elecciones al Parlamento de Andalucía asciende a 771.164,18 euros.

También fue presentado a la presidenta del Parlamento, el 4 de mayo, el informe del sector público empresarial de la Junta de Andalucía, año 2002; un sector empresarial compuesto por 48 empresas públicas participadas mayoritariamente por la Junta.

\section{Defensor del Pueblo Andaluz.}

Presentó la Memoria anual ante el Parlamento el 24 de mayo. En el ámbito de la supervisión del funcionamiento de la Administración Pública Andaluza, las intervenciones del Defensor del Pueblo Andaluz han seguido manteniéndose en los elevados niveles de años anteriores, que se han materializado en la recepción y tramitación de 4.964 nuevas quejas (26 más que el año anterior), de las cuales 249 fueron iniciadas de oficio por la propia Institución, que continua con el criterio de actuar en todas aquellas situaciones de relevancia y trascendencia social que pudieran afectar al ámbito de los derechos de los ciudadanos o colectivos sociales.

En cuanto a los sectores objeto de mayor número de quejas por parte de los ciudadanos destaca el funcionamiento de la Administración de Justicia -di- 
lación de los procesos- y prisiones -motivadas fundamentalmente por el masivo traslado de presos andaluces a otras Comunidades Autónomas-, la vivienda, la educación y la asistencia sanitaria. Cabe destacar también, en relación con este balance de quejas, el incremento que han experimentado las reclamaciones que afectan a materias relacionadas con el medio ambiente, que se han incrementado en un $171 \%$, lo que pone de manifiesto el aumento de la sensibilidad y el interés creciente de la sociedad andaluza por aquellas cuestiones que afectan a la protección de sus derechos en esta parcela.

Otra de las tareas que la Institución viene desarrollando es la elaboración y puesta disposición del Parlamento de Andalucía y de toda la sociedad de Informes Especiales sobre investigaciones en diversas problemáticas sociales. Durante el año 2004 se han elaborado cuatro de estos Informes, dos de los cuales están especialmente orientados al estudio de situaciones que afectan de forma singular a los derechos de los menores: el de Menores Inmigrantes en Andalucía (presentado al Parlamento el 13 de enero de 2004) y el primer Informe Anual sobre la situación de los Menores en Andalucía, en el que se contiene una análisis de las principales quejas tramitadas en esta materia, así como una valoración general de la situación de este trascendente sector de la población andaluza. Otros informes extraordinarios han sido el de la incidencia de las drogas en la población inmigrante y extranjera comunitaria (presentado el 28 de julio de 2004. (Publicado en el BOPA núm. 53, de 9 de septiembre); y el de Discapacitados y acceso al empleo en las Administraciones Públicas, donde se abordan problemáticas específicas que afectan situaciones y colectivos sociales con gran repercusión social (presentado al Parlamento el 8 de noviembre de 2004, pendiente de publicación a final de dicho año)

En cuanto a actuaciones institucionales reseñables hay que destacar las intervenciones en materia de protección y defensa del territorio frente a actividades contra el suelo no urbanizable por obras y edificaciones no autorizables, dentro de las cuales se inscriben los trabajos realizados conjuntamente con la Fiscalía del Tribunal Superior de Justicia de Andalucía y los Fiscales especializados en materia de protección medioambiental y urbanística, acordándose conclusiones de gran interés para la cooperación recíproca de estas Instituciones en esta materia y la concienciación social e implicación de las distintas Administraciones Públicas.

Es destacable la comparecencia del Defensor del Pueblo Andaluz en la Comisión Parlamentaria de reforma del Estatuto de Autonomía de Andalucía. El Defensor aportó un documento sobre sus propuestas (puede ser consultado en la dirección de internet de esta Institución: www.defensor-and.es), en- 
tre las que destaca la inclusión de un Título sobre Derechos en el futuro Estatuto que persigue el afianzamiento y extensión de las garantías para el efectivo disfrute de los derechos y libertades por parte de la ciudadanía andaluza. Asimismo, se hace referencia en esta propuesta a los nuevos aspectos y necesidades sociales que se han puesto de manifiesto en los últimos tiempos como consecuencia de los vertiginosos cambios acaecidos en nuestra sociedad, en general, y en la andaluza, en particular, en los más diversos ámbitos.

La propuesta, por último, también persigue perfeccionar la configuración del Defensor del Pueblo Andaluz para el cumplimiento de los cometidos que tiene asignados, a la luz de sus dos décadas de experiencia en el ejercicio de sus funciones garantizadoras, así como para responder eficazmente a los nuevos retos y situaciones que esa dinámica social exige de este tipo de Instituciones. 